\title{
131 I UPTAKE IN NONLACTATING BREAST RELATED TO PAPILLARY THYROID CARCINOMA
}

Osakidetza

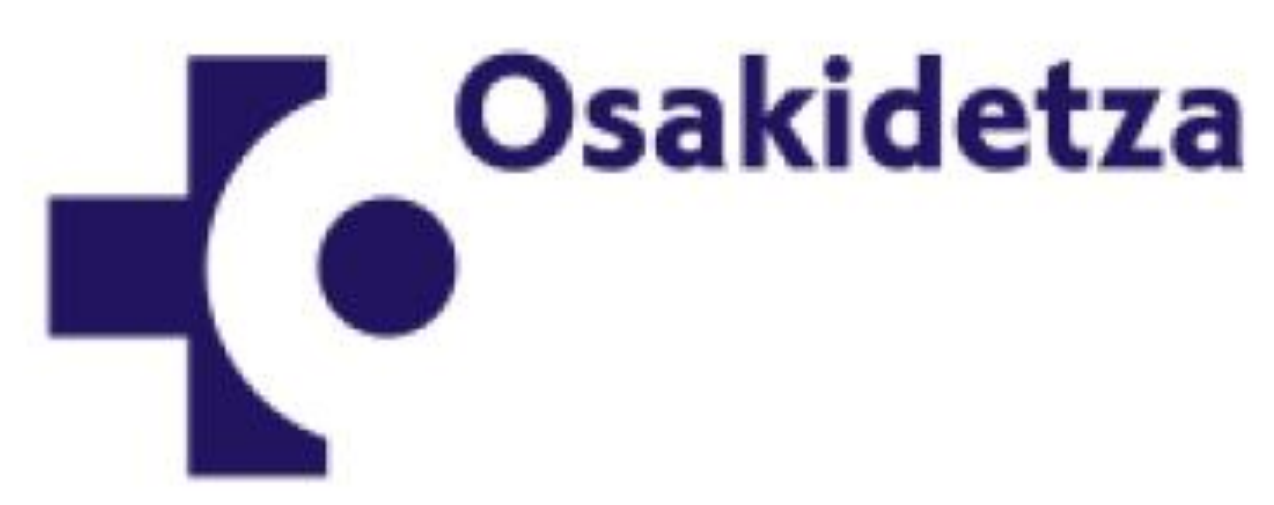

Authors:, Perez Yeboles Josu, Larrañaga Unanue IhintzaCillero Etxebeste loana*

Endocrinology Department. Hospital Mendaro (Gipuzkoa, Spain)

*Nuclear Medicine. Instituto Onkologikoa (Donostia, Gipuzkoa, Spain)

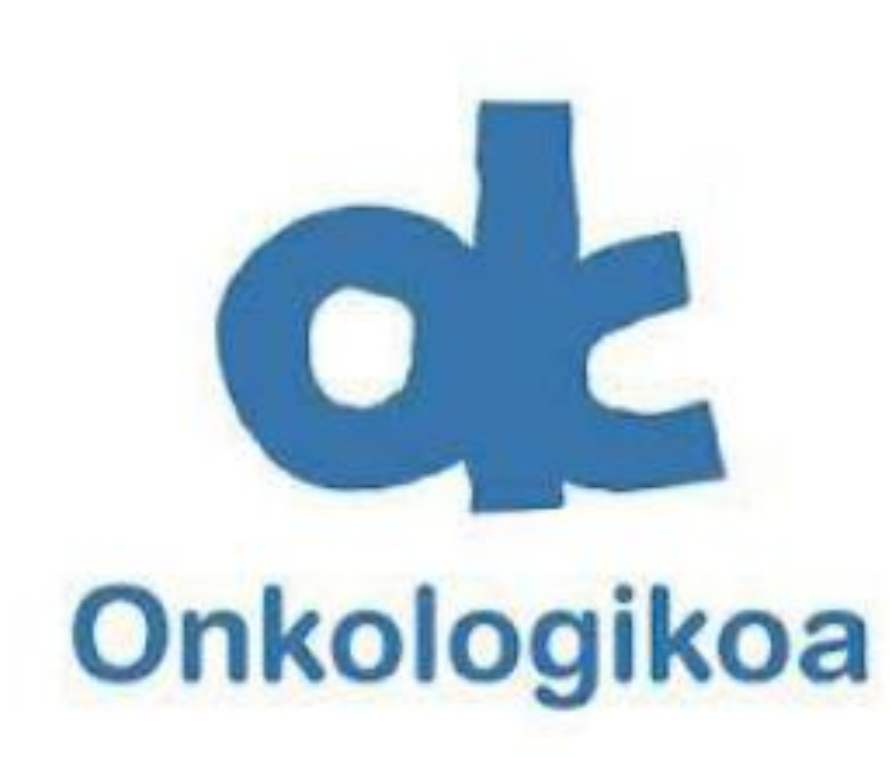

Onkologikoa

\section{INTRODUCTION}

Radioiodine whole-body scintigraphy (WBS) has been widely used for detection of differentiated thyroid cancer (DTC), based on the marked storage of iodine in functioning thyroid tissue. However, radioiodine uptake is not specific for thyroid gland. lodine accumulation in lactating breast has been demonstrated, but it is rare in nonlactating breast

\section{CASE REPORT}

\begin{abstract}
A 74-year-old-woman who underwent near-total thyroidectomy in 1988 due to a multinodular non-toxic goiter, presented during the surveillance a suspicious left thyroid nodule. Ultrasound (US) guided fine needle aspiration (FNA) was performed and the cytologic examination showed a follicular proliferation with atypia. A total thyroidectomy and selective lymphadenectomy was realised because of macroscopic lymph node affectation. Pathology examination showed a $1.1 \mathrm{~cm}$ papillary thyroid carcinoma and regional lymph node metastases. Radioiodine ablation with $100 \mathrm{mCi}^{131}$ I was realised after the surgery. WBS was negative for extrathyroidal metastases. Patient presented progressive elevation of thyroglobulin $(34 \mathrm{ng} / \mathrm{ml})$ and increasing antithyroglobulin antibodies (307 UI/mL). US identified left III cervical compartment lymph node involvement. $150 \mathrm{mCi}{ }^{131} \mathrm{I}$ was administrated after recombinant human thyrotropin injection. Postablative WBS showed focal intense uptake in left cervical region and increase uptake in bilateral breasts (Fig 1). Hyperprolactinemia (serum prolactin $110 \mathrm{mcg} / \mathrm{mL}$ ) was found in biochemical test and a magnetic resonance imaging detected a pituitary microadenoma (6 $\mathrm{mm}$ ) (Fig 2).

Medical treatment was rejected due to the postmenopausal condition.
\end{abstract}

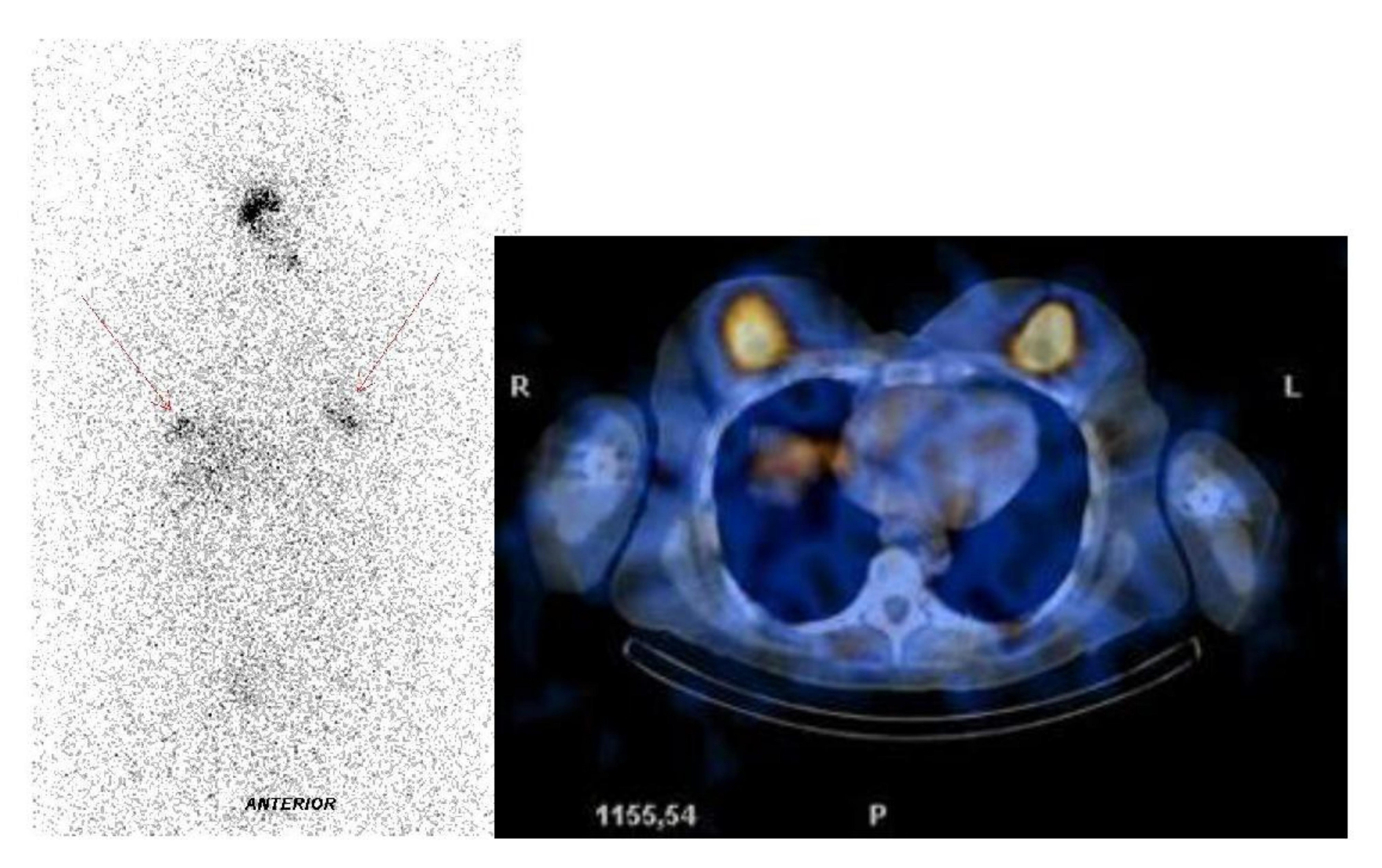

Figure 1. WBS

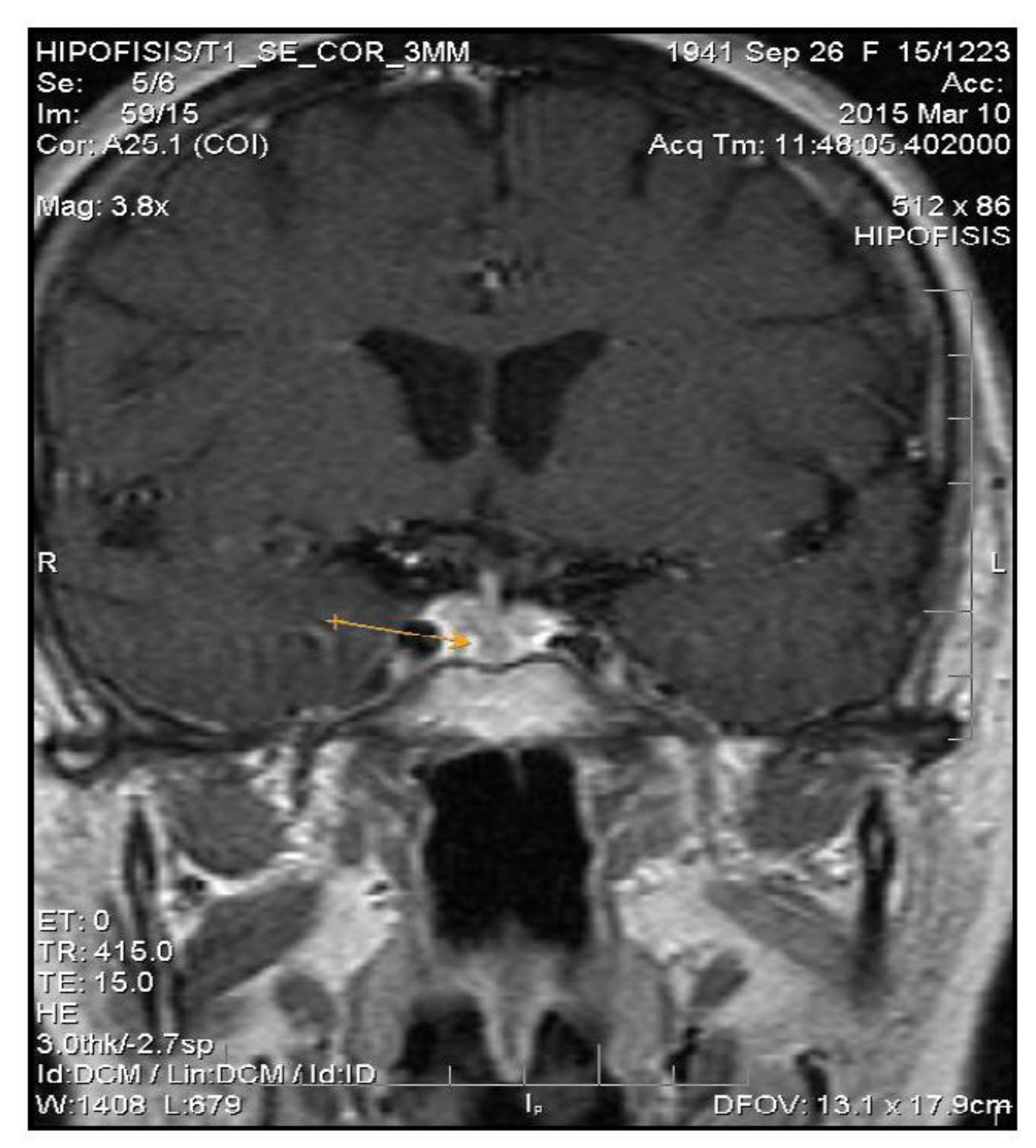

Figure 2. MRI (coronal image T1)

\section{CONCLUSIONS}

Radioactive iodine uptake in functioning thyroid tissue is mediated by enhanced expression of sodium-iodide symporter (NIS). This case illustrates that not only lactating breast can concentrate iodine, but also in nonlacting mammary gland the presence of prolactin hypersecretor pituitary gland tumour can induce increased NIS expression and therefore prominent accumulation of iodine. 